\title{
O gerencialismo, reforma do Estado e da educação no Brasil
}

\author{
Sonayra da Silva Medeiros \\ Prefeitura Municipal de Campina Grande \\ Melânia Mendonça Rodrigues \\ Universidade Federal de Campina Grande
}

\section{Resumo}

artigo discute formulações do Centro Latino-Americano de Administração para o Desenvolvimento (CLAD) e sua disseminação nos países da América Latina, na década de 1990. Analisa propostas do Plano Diretor de Reforma do Aparelho do Estado brasileiro (1995), objetivando compreender repercussões do gerencialismo na gestão da escola pública. Entende-se que programas e projetos implementados nas redes públicas, sob a perspectiva gerencial, decorrem do processo de modernização da gestão, pautado nos princípios neoliberais. Incluídos no contexto das parcerias público-privadas, a partir da atuação de um grupo restrito de líderes/gerentes, tais programas gerencialis-

216 tas colidem, frontalmente, com a gestão democrática da escola pública.

Palavras-chave: Gerencialismo. Política educacional. Gestão escolar.

\section{The management, reform of State and education in Brazil}

\section{Abstract}

This article discuss formulations of Latin American Administration Center for Development and their dissemination in Latin America countries, in 1990 decade. The article analyses proposals of General Plan of Brazil State Reform (1995), having as objective to understand the repercussions of administration in public school management. We understand that programs and projects applied in public schools, under a management view, passes by this process of management modernization, based in new liberalism principals. Included in context of private-public associations, as actuation of a limited group, formed by leaders / managers. These management programs collides, frontally, with the public school democratic administration.

Keywords: Management. Educational politic. School administration. 


\section{El gerencialismo, la reforma del Estado y de la educación en Brasil}

\section{Resumen}

El artículo discute las formulaciones del Centro Latinoamericano de Administración para el Desarrollo (CLAD) y su difusión en América Latina, en la década de 1990. Analiza el Plan Director de la Reforma del Estado brasileño (1995), con objetivo de comprender la repercusión del gerencialismo en la gestión de las escuelas públicas. Entendemos que los programas y proyectos implementados en las redes públicas, se derivan de la modernización de la gestión, basada en los principios neoliberales. Se incluyen en el marco de asociaciones público-privadas, a partir del trabajo de un pequeño grupo de líderes/gerentes, esos programas chocan con la gestión democrática de las escuelas públicas.

Palabras-clave: Gerencialismo. Política educacional. Gestión escolar.

\section{Introdução}

Objetivando compreender repercussões do gerencialismo, na gestão da escola pública, o texto discute as formulações do Centro Latino-Americano de Administração para o Desenvolvimento (CLAD), disseminadas nos países da América Latina, a partir da década de 1990, e analisa as propostas do Plano Diretor de Reforma do Aparelho do Estado brasileiro (BRASIL, 1995).

Nessa perspectiva, para tratar das mudanças na administração pública brasileira, deve-se partir de uma contextualização histórica da reforma gerencial. Na sequência, a abordagem de conceitos e mudanças na administração pública, especificando o ângulo de análise sobre a reforma do Estado no Brasil e a modernização da gestão, fundamenta essa discussão sobre os possíveis efeitos da implementação de propostas gerenciais no campo da educação, em especial, no âmbito da escola pública brasileira.

\section{Gerencialismo: conceito e contextualização}

A crise do capitalismo dos anos 1970 engendra o "esfacelamento" (ABRUCIO, 1997) do tipo de Estado que predominara, desde o final da Segunda 
O gerencialismo, reforma do Estado e da educação no Brasil

Guerra Mundial, nos países de capitalismo avançado, compreendendo três dimensões interligadas, quais sejam: econômica, social e administrativa. A dimensão econômica keynesiana, caracterizada pela ativa intervenção estatal na economia; a dimensão social, caracterizada pelo Welfare State, que assegurava políticas públicas na área social; e a dimensão administrativa, relacionada à forma de organização do Estado, ou seja, ao modelo burocrático weberiano.

Como uma das estratégias para enfrentamento dessa crise, e no âmbito do processo de redefinição do papel do Estado, emerge um novo paradigma de administração pública, o modelo gerencialista ou New Public Management (NPM). Esse modelo, segundo Costa (2010), é fruto de longa maturação de ideias que germinavam nos meios acadêmicos desde os anos 1950, com heranças da nova economia institucional ou neoinstitucionalismo econômico e da Teoria da Escolha Racional ou Escolha Pública (Public Choice)'.

Segundo o autor, as propostas do NPM, implementadas na Inglaterra, inicialmente, pelo governo conservador de Margareth Thatcher (1979), eram veiculadas, a partir dos anos de 1960, por institutos ${ }^{2}$ que "[...] centraram seu trabalho na crítica ao modelo de intervenção social democrata e na formulação de um programa baseado nas premissas do livre mercado e do neoliberalismo" 218 (COSTA, 2010, p. 149-150).

Nos Estados Unidos, ainda analisa Costa (2010, p. 151), com a eleição de Ronald Reagan em 1980, a grande frente de batalha deu-se no plano ideológico, uma vez que "[...] o governo americano alcançou vitórias sucessivas, conseguindo utilizar sua influência para impor o ideário liberal e o programa de reformas, nele inspirado, a todos os organismos internacionais."

A partir de 1984, programas semelhantes foram implementados em países como Austrália e Nova Zelândia, onde as reformas foram iniciadas sob governos trabalhistas e aprofundadas, posteriormente, pelos governos conservadores (COSTA, 2010). Na Inglaterra, aconteceu o contrário, passando das mãos dos conservadores para os trabalhistas em 1997. Nesse sentido, o autor destaca que:

[...] o governo de Tony Blair persistiu com a mesma política de gestão adotada pelos conservadores, combinando economia de livre mercado, regulação estatal e terceirização de serviços sociais. Para sustentar ideológica e conceitualmente a deriva neoliberal do trabalhismo, Blair foi buscar na terceira via os argumentos de que 
precisava para eleger o mercado como força progressista (COSTA, 2010, p. 150).

Ao referenciar os estudos de David Osborne e Ted Gaebler, Costa (2010) explica que foram analisadas e sistematizadas algumas das iniciativas relacionadas ao gerencialismo, em um livro intitulado "Reinventando o governo". Essa reinvenção do governo

[...] compreendia a adoção de uma série de princípios capazes de torná-lo catalisador, pertencente à comunidade, responsável, competitivo, orientado por missões, avaliado por resultados, voltado para as necessidades dos clientes, empreendedor, preventivo, descentralizado e orientado para o mercado. Todos esses princípios se identificam com o programa da NPM, que buscava fazer o governo funcionar melhor, custar menos e obter resultados (COSTA, 2010, p. 152).

Tais ideias foram incorporadas à administração pública, nos Estados Unidos, no governo democrata de Bill Clinton. Nesses contextos, "[...] a NPM também foi tributária de todas as inovações introduzidas no campo da gestão empresarial, a partir da reestruturação produtiva caracterizada pelo pós-fordismo" (COSTA, 2010, p. 152).

autor explicita que a new public management funda-se no pressuposto da racionalidade econômica. $\bigcirc$ espaço de intervenção do Estado se reduz, concentrando-se em funções regulatórias; as políticas sociais de caráter compensatório são focalizadas e têm sua execução delegada a terceiros; os cidadãos são tratados como clientes; bens e serviços públicos, avaliados por critérios de mercado; organismos públicos passam a adotar métodos empresariais de gestão (management), com foco na eficiência; funcionários públicos avaliados por critérios de desempenho, próximo aos utilizados nas empresas privadas (COSTA, 2010).

Estudando a implementação desse modelo de gestão, Cabral Neto (2009) destaca três fases do gerencialismo, a saber: o modelo gerencial puro; o consumerism, e o Public Service Orientation (PSO).

Segundo o autor citado, o modelo gerencial puro estava de acordo com "[...] as teses do neoliberalismo, que buscava tornar o setor público mais próximo possível do setor privado, considerado, pelos seus ideólogos, como sendo mais eficiente e produtivo" (CABRAL NETO, 2009, p. 178). A segunda 
fase, correspondente ao consumerism, caracterizava-se pela flexibilidade da gestão, qualidade dos serviços públicos e prioridade às demandas do consumidor (CABRAL NETO, 2009).

Na Public Service Orientation (PSO), terceira fase do gerencialismo, ocorre uma ressignificação no conceito de descentralização, que passa a enfatizar a aproximação dos serviços públicos aos consumidores. No $\mathrm{PSO}^{3}$, a descentralização está relacionada ao papel atribuído aos cidadãos, "[... ] o governo local torna os cidadãos capazes de participação política dentro de um conceito mais amplo - o da esfera pública" (CABRAL NETO, 2009, p. 183). 0 autor ainda destaca que essa terceira fase do modelo gerencial (PSO) representa um imbricamento das ideias gerenciais concebidas no âmbito do setor privado com as ideias já formuladas para o setor público nas fases anteriores do modelo gerencial.

No plano administrativo, Castro (2007) explica que, com a expansão capitalista do pós-Segunda Guerra Mundial, a gestão inspirava-se no modelo burocrático de administração weberiano, o qual, a partir da década de 1980, passou a ser considerado ineficiente, em contraposição ao modelo gerencial.

Cabral Neto (2009) aponta algumas tendências, relativas ao modelo 220 de gerenciamento público, alinhadas às teses do modelo gerencial, ponderando que elas não se expressam da mesma forma em todos os espaços. Conforme o autor, constituem medidas adotadas pelo modelo gerencial:

- incentivo às parcerias em todos os níveis;

- adoção de mecanismos de avaliação de desempenho lqualidade e produtividade);

- maior autonomia em todos os níveis hierárquicos do sistema (horizontalização da gerência e do processo decisório);

- descentralização (tanto mais próximo do cidadão, melhor a qualidade do serviçol;

- adoção do planejamento estratégico (pensar a política a médio e longo prazos);

- flexibilização das regras que regem a burocracia pública (negociação coletiva, introdução de ganhos de produtividade, novos critérios de promoção);

- profissionalização do servidor público (investimento na formação de recursos humanos com ênfase na aquisição de múltiplas competências); 
- desenvolvimento de habilidades gerenciais latuar ao mesmo tempo em várias funções - dotar o trabalhador de múltiplas versatilidades) (CABRAL NETO, 2009, p. 184).

Diversos atores políticos investem, desde os anos 1990, na defesa da implantação do modelo gerencial, dentre os quais se destaca, na América Latina, o Centro Latino-Americano de Administração para o Desenvolvimento (CLAD)4, organismo cuja missão é colaborar para a difusão e o debate das ideias e práticas sobre a reforma do Estado, particularmente, da administração pública (CLAD, 1998). Cumpre, desse modo, um papel estratégico na promoção da reforma gerencial do Estado no subcontinente, com base no entendimento de que tal reforma "[...] oferece as melhores respostas aos desafios econômicos, sociais e políticos presentes na América Latina" (CLAD, 1998, p. 5).

Nessa perspectiva, o Centro Latino-Americano de Administração para o Desenvolvimento (CLAD) participou na disseminação das ideias em defesa do modelo gerencial. O documento do CLAD "Uma Nova Gestão Pública para América Latina" - preparado pelo Conselho Científico do CLAD e aprovado pelo Conselho Diretor do CLAD na sua sessão, de 14 de outubro de 1998 -, apresenta propostas para novos rumos da administração pública para os países da América Latina.

Ao abordar a crise do Estado no final da década de 1970, o referido documento analisa que a Reforma do Estado tornou-se tema central da agenda política mundial, com a necessidade de reestabelecer seu equilíbrio fiscal e equilibrar o balanço do pagamento dos países em crise. Nesse contexto, explica que, em um primeiro momento, a resposta à crise foi a neoliberal-conservadora, propondo a redução do tamanho do Estado e o predomínio total do mercado. Tal proposta, conforme salientada no documento, fazia pouco sentido econômico e político, sendo fundamental se pensar em novas soluções. Constatou-se, portanto, que, em vez do desmantelamento do aparelho estatal, seria necessária a sua reconstrução. Ou seja, o Estado para o século XXI seria, como é defendido, o Estado "necessário", o qual,

[...] além de garantir o cumprimento dos contratos econômicos, deve ser forte o suficiente para assegurar os direitos sociais e a competitividade de cada país no cenário internacional. Busca-se, desse modo, uma terceira via entre o laissez faire neoliberal e o antigo modelo social-burocrático de intervenção estatal ICLAD, 1998, p. 3). 
No caso da América Latina, conforme o CLAD, um balanço das primeiras reformas mostra que o ajuste estrutural, com o objetivo de redução do Estado, não resolveu uma série de problemas básicos dos países do subcontinente. Logo, o maior desafio era compatibilizar as tendências mundiais de mudanças com as especificidades da região. De acordo com as formulações do CLAD (1998), - Estado deve alterar as antigas políticas protecionistas, tomando medidas que induzam, no novo ambiente econômico mundial, a competitividade das empresas.

Nessa perspectiva, para o CLAD (1998), a outra tendência estrutural é a mudança do papel do Estado nos setores econômico e social. Ou seja, em termos econômicos, o aparelho estatal deve concentrar suas atividades na regulação, com privatizações e criação de agências reguladoras. Além disso, - Estado deve desenvolver sua "capacidade estratégica" de atuar junto ao setor privado e à universidade, possibilitando o aumento da competitividade das empresas. Na área social, a alternativa é reforçar o papel do Estado como formulador e financiador das políticas públicas. Para isso, conforme defende,

[...] torna-se fundamental o desenvolvimento da capacidade catalisadora dos governos em atrair a comunidade, as empresas ou - Terceiro setor para compartilhar a responsabilidade pela execução dos serviços públicos, principalmente os de saúde e educação básica (CLAD, 1998, p. 4).

Nesse documento, é apresentada uma ressalva ao caso latino-americano, em que o Estado deverá intervir diretamente quando não houver condições sociais mínimas de compartilhar as atividades com a sociedade. Recomenda-se, pois, identificar as situações, nas políticas públicas, em que os serviços poderão ser prestados, por exemplo, por entidades públicas não estatais.

As questões regionais que precisavam ser consideradas na reforma do Estado em países da América Latina eram: a consolidação da democracia, a retomada do desenvolvimento econômico e a redução da desigualdade social. Entende-se que:

[...] é preciso reforçar as formas democráticas de relacionamento entre o Estado e a sociedade, aumentando o grau de accountability (responsabilização) do sistema. Com isso, busca-se capacitar os cidadãos para controlar as políiticas públicas, podendo torná-las, a um só tempo, mais eficientes e com melhor qualidade ICLAD, 1998, p. 5, grifo do autor). 
A reforma gerencial da administração, no documento do CLAD (1998), é considerada fundamental para aumentar a governança ${ }^{6}$ do Estado, bem como para melhorar a governabilidade democrática do sistema político. $\bigcirc$ modelo gerencial defendido, conforme explicitação no documento, buscando possibilitar uma relação mais democrática entre Estado e sociedade, pressupõe e busca aprofundar os mecanismos democráticos de responsabilização e "transparência" da administração pública. Nesse sentido, "[... não se trata, portanto, apenas de criar um Estado mais efetivo e eficiente; é fundamental instituir um Estado verdadeiramente democrático na América Latina" (CLAD, 1998, p. 8).

As principais características desse modelo administrativo, consideradas essenciais pelo CLAD (1998), no que concerne à modernização gerencial do Estado nos países da América Latina, são as seguintes:

a) a profissionalização da alta burocracia, defendendo ser necessária uma elite burocrática tecnicamente preparada e motivada. Esse ponto é considerado fundamental na formulação, supervisão e regulação das políticas;

b) a administração pública transparente e administradores responsabilizados democraticamente perante a sociedade;

c) a descentralização da execução dos serviços públicos, buscando, conforme destaca, além de ganhos de eficiência e efetividade, aumentar a fiscalização e o controle social dos cidadãos sobre as políticas públicas;

d) a desconcentração organizacional nas atividades exclusivas do Estado, uma vez que se parte do entendimento de que a execução das funções deve ser delegada, pelos órgãos centrais, para as agências descentralizadas;

e) o controle dos resultados, em vez de controle das normas e procedimentos, característico do modelo burocrático weberiano. Nesse processo, são necessários, conforme o CLAD, três mecanismos, quais sejam: o contrato de gestão, efetuado entre órgão central e agências descentralizadas, com metas quantitativas e qualitativas, com penalidades, premiações ou formas de corrigir os erros; alteração da rígida hierarquia que caracterizava o modelo burocrático weberiano; e investimento em construção de instituições e no treinamento de pessoal qualificado;

f) maior autonomia gerencial das agências e de seus gestores, que deve ser complementada por novas formas de controle, buscando, primordialmente, ganhos de eficiência e efetividade das políticas; 
g) distinção necessária de duas formas de unidades administrativas autônomas: a que envolve as agências que realizam atividades exclusivas de Estado, caso em que a descentralização tem como finalidade aumentar a flexibilidade administrativa do aparelho estatal; e a que atua nos serviços sociais e científicos;

h) prestação dos serviços voltada para o cidadão-usuário, que, segundo - Centro Latino-Americano, trata-se de uma revolução na administração pública. E expõe que "[...] com esta mudança, os cidadãos devem participar tanto da avaliação como da gestão das políticas públicas, especialmente na área social" (CLAD, 1998, p. 14);

i) aumento da responsabilização do servidor público em três aspectos:

i) Perante a sociedade, tornando a administração pública mais transparente, voltada para a prestação de contas; ii) Perante os políticos eleitos nos termos da democracia representativa, sejam do governo sejam da oposição; e iii) Perante os representantes formais e informais da sociedade que estejam atuando junto à esfera pública não estatal (CLAD, 1998, p. 15).

$224 \quad$ No documento do CLAD (1998), percebe-se a crítica feita ao modelo burocrático weberiano, expondo que é necessário superar esse modelo de "rigidez hierárquica" e responsabilizar os funcionários públicos por metas, conscientizando-os da missão de sua organização. Para tanto, considera que a melhor forma é delegar poder (empowerment) e autonomia aos gerentes. Por isso, defende que, para os Estados latino-americanos transformarem, efetivamente, as estruturas da administração pública, é preciso investir em pessoal qualificado e numa administração pública baseada nos resultados, com avaliação do desempenho individual e institucional.

Segundo o CLAD (1998), há, na reforma gerencial do Estado, uma proposta de transferência da prestação dos serviços públicos sociais ao espaço público não estatal, situação que ocorre, conforme complementa, por quatro vantagens: a primeira se refere à necessidade de flexibilização da administração pública, sem atingir os princípios básicos do Estado de direito, de tratamento igual a todos os cidadãos. A segunda vantagem é a motivação por parte dos grupos sociais que assumem o espaço público não estatal. A terceira é que o conceito de público não estatal mostra que o Estado precisa aumentar sua capacidade de cooperação com a comunidade, o Terceiro Setor e o mercado, para 
possibilitar melhorias na prestação dos serviços públicos. A quarta vantagem do setor público não estatal é que esse espaço pode tornar mais democrática a prestação e a gestão dos serviços públicos. Nessa perspectiva, salienta-se que:

[...] o revigoramento do Estado latino-americano fará com que ele se concentre e ganhe efetividade na promoção da educação, saúde, habitação, programas de renda básica, desenvolvimento científico- tecnológico e comércio exterior. Além disso, a implantação bem sucedida do modelo gerencial capacitará o Estado a oferecer fundamentos macroeconômicos estáveis, criando condições para a elevação do investimento privado nacional e multinacional, bem como para aumentar a competitividade internacional dos países da América Latina (CLAD, 1998, p. 14-15).

Diante de tais argumentações, o CLAD (1998) ainda tenta deixar claro que a reforma gerencial proposta não opta pelos princípios do mercado como o ordenador por excelência dos novos rumos do setor público. Reforça, nesse sentido, que o caminho para a modernização da administração pública "[...] passa pela redefinição das relações entre a sociedade e o Estado, construindo uma esfera pública que, de fato, envolva a sociedade e os cidadãos na gestão das políticas" (CLAD, 1998, p. 16). Defende, também, maior responsabilização dos funcionários públicos frente à sociedade e ao sistema político.

Esse organismo atua disseminando suas ideias em defesa da reforma gerencial do Estado e se posicionando em defesa de práticas pretensamente democráticas, o que faz questionar em que medida a democracia é considerada no processo de decisão dos membros atuantes nos espaços públicos, cujas ações ficam submetidas, via de regra, às decisões dos qualificados "gerentes". Nesse sentido, para evitar questionamento à defesa da reforma gerencial, o CLAD ressalta que defende uma proposta "essencialmente democrática". Tal modelo, conforme sua compreensão:

[...] pressupõe transparência na administração pública, amplia o espaço do controle social e transforma o público - e não o mercado auto suficiente - no conceito direcionador da reforma; renovando o papel da democracia representativa e da afirmação dos direitos humanos, inclusive dos 'direitos republicanos' na proteção do patrimônio público (CLAD, 1998, p. 17). 
E, apoiando, integralmente, o projeto de reforma gerencial do Estado latino-americano, orienta os reformadores, ressaltando que:

[...] para lograr sucesso, os propositores da Reforma Gerencial terão que, primeiramente, convencer os vários setores em relação ao seu diagnóstico; depois, os reformadores terão que estabelecer novas alianças, baseadas nos princípios democráticos-republicanos, com a alta burocracia pública, o empresariado, os trabalhadores, os intelectuais. Esse processo provavelmente será demorado, mas o importante é ter consciência de que se trata da reforma que preparará o Estado para o século XXI (CLAD, 1998, p. 17).

Os defensores do modelo gerencial utilizam-se do discurso em prol da participação dos cidadãos e do controle social sobre as políticas públicas, assim como se posiciona o CLAD (1998), relacionando as mudanças na administração pública a novas possibilidades de democratização. Compreende-se, contudo, que, nessa defesa da reforma gerencial, há maior interesse em responsabilizar os cidadãos pelos resultados, sendo enfática a utilização de mecanismos de fiscalização e de premiação, de avaliação de desempenho individual e institu226 cional, pautada em princípios de eficiência e produtividade.

gerencialismo vem sendo intensificado nas políticas implementadas em nosso país, e evidenciado em vários estados brasileiros, por meio de programas e projetos considerados exitosos, servindo de inspiração para novos gestores. É o que se pode observar em âmbito educacional, por exemplo, com a implantação de políticas de remuneração por desempenho, objetivadas no pagamento de bônus ou de salários adicionais em função dos resultados obtidos ${ }^{7}$.

Na perspectiva gerencial, conforme destaca Carvalho (2009), pretende-se que os governos recorram mais aos incentivos e menos à imposição de regulamentos. Nesse sentido,

[...] a avaliação representaria simultaneamente um importante instrumento de controle, regulação e fiscalização, ou seja, verificaria se as metas estabelecidas tinham sido alcançadas, esclareceria os 'consumidores' sobre as escolas que merecessem ser consideradas como de qualidade, permitiria que 'as forças do mercado' operassem com força total e que os indivíduos ficassem livres para efetuar escolhas; ao mesmo tempo, permitiria medir o rendimento dos 
investimentos educativos e levantaria indicadores para o repasse de verbas públicas (CARVALHO, 2009, p. 1151 ).

Entende-se que as formulações do CLAD, bem como as concepções explícitas em seus documentos, auxiliam a compreender a base teórica do modelo gerencial, a qual também se faz presente na administração pública brasileira, no contexto da Reforma do Estado. As ideias gerencialistas no Brasil foram intensificadas pelas discussões de Bresser Pereira e, estabelecidas, a partir da elaboração do Plano Diretor de Reforma do Aparelho do Estado (1995), o qual respaldou ações no espaço público sob a lógica gerencial.

\section{Reforma do Estado brasileiro e mudanças na administração pública}

A redefinição do papel do Estado brasileiro, bem como a nova configuração da sociedade civil, está inserida no contexto de mudanças ocorridas em cenário mundial. Tais mudanças, amplamente discutidas e enfatizadas por estudiosos, partem de uma contextualização de como o Estado foi se configurando no mundo, ao longo de determinados momentos históricos.

Costa (2010), contextualizando historicamente as transformações do Estado, a organização governamental e a administração pública, ressalta a importância de se entender a lógica de intervenção do Estado na vida social. Nessa discussão, aponta a influência de Getúlio Vargas no sentido do primeiro esforço deliberado, sistemático e continuado de modernização administrativa, considerando que as reformas realizadas na "Era Vargas" (1930-1954) pautaram as subsequentes, do período denominado pelo autor de "Era Vargas sem Vargas (1955-1989)", também marcado pela forte presença do Estado na economia, regulando as relações de trabalho. Conforme explica, "[...] o Brasil persistiu na política de industrialização via substituição de importações e no dirigismo estatal até o final da ditadura militar e mesmo até o governo de transição (1985-1990)" (COSTA, 2010, p. 79).

De acordo com a análise do autor, a partir de 1990, com o governo Collor, há um movimento no sentido de romper com os pressupostos da Era Vargas, através da abertura comercial, da desestatização, da desregulamentação socioeconômica, da reforma da previdência e da reforma administrativa. 
O gerencialismo, reforma do Estado e da educação no Brasil

Essas mudanças produzem uma Era de "Vargas contra Vargas". Contudo, o autor afirma que, mesmo com essas intervenções, não houve alteração profunda da estrutura social, tampouco foram firmadas, ainda, as bases de um novo modelo de crescimento econômico.

Nessa perspectiva, a reforma gerencial, não obstante os equívocos políticos, conceituais e operacionais, salienta Costa (2010), começou ainda no governo Collor. Conforme complementa,

[...] na medida em que o país se transformava econômica, social e politicamente, a administração pública se ampliava, se diferenciava e se aparelhava sempre aumentando a oferta de bens e serviços. Assim, não obstante os avanços persistentes e os eventuais recuos, a administração pública se modernizou, ganhando em eficiência, especialização técnica, moralidade, publicidade e transparência. Entretanto, esse processo de transformação sempre deixou em segundo plano a questão democrática e a teleologia das reformas e da própria máquina pública (COSTA, 2010, p. $117)$.

No período que se seguiu ao impeachement do presidente Collor e 228 no início do governo Fernando Henrique Cardoso, foi evidenciado o tema da reforma do Estado. Os dois governos de FHC voltaram-se, prioritariamente, "[...] à reestruturação do Estado nas suas funções econômicas e ético-políticas. De produtor direto de bens de serviços, o Estado passou a coordenador de iniciativas privadas" (NEVES, 2005, p. 92).

Tendo em vista essas considerações, a discussão sobre a reforma gerencial não pode preterir o estudo do Plano Diretor de Reforma do Aparelho do Estado (1995) e o momento histórico de reformas que é vivenciado no Brasil a partir da década de 1990.

A reforma do Estado no Brasil foi apontada como estratégia para superação da crise. Para tanto, foi criado o Ministério da Administração e Reforma do Estado (MARE), o qual apresentou o Plano Diretor da Reforma do Estado, que "[...] define objetivos e estabelece diretrizes para a reforma da administração pública brasileira [...]" (BRASIL, 1995, p. 06), desenvolvido na primeira gestão de Fernando Henrique Cardoso, sob a coordenação do ministro Luiz Carlos Bresser Pereira. 
conteúdo do Plano Diretor, na gestão de Fernando Henrique Cardoso, já apontava "novos" rumos estabelecidos para administração pública, talvez ainda não com tanta clareza dos efeitos dessa reforma como se pode identificar, atualmente, nas políticas educacionais.

Costa (2010) analisa que, apesar de tratar aspectos da governabilidade, governança e do funcionamento do gasto público, a maior parte da argumentação no documento era para mostrar o papel central do Estado na crise econômica dos países da America Latina.

É importante salientar que a reforma do Aparelho do Estado ${ }^{8}$, assim como explicitada no Plano Diretor (1995), é uma das medidas relevantes incluída no contexto maior de reforma do Estado. $O$ documento do Plano Diretor, na explicação da diferença entre tais reformas, destaca que:

[...] a reforma do Estado é um projeto amplo que diz respeito às várias áreas do governo e, ainda, ao conjunto da sociedade brasileira, enquanto que a reforma do aparelho do Estado tem um escopo mais restrito: está orientada para tornar a administração pública mais eficiente e mais voltada para a cidadania (BRASIL, 1995, p. 12).

modelo conceitual da Reforma do Aparelho do Estado propõe dois tipos de propriedade pública - a propriedade pública estatal e a propriedade pública não estatal. A propriedade pública estatal seria o conjunto de bens sob controle estatal, e a propriedade pública não estatal compreenderia todos aqueles bens que, embora não sejam propriedades do estado, servem ao interesse público (COSTA, 2010).

A partir da reforma da aparelhagem estatal, segundo Neves (2004), as políticas públicas passam a apresentar uma nova dinâmica:

As políticas governamentais passam a ser definidas por um núcleo estratégico situado no Executivo central, executadas por parceiros na 'nova' sociedade civil e posteriormente avaliada por esse núcleo central, dinâmica da chamada administração gerencial. As políticas sociais em geral, começam a se constituir em serviços não-exclusivos do Estado, ou seja, que podem ser exercidos simultaneamente pelo Estado, pela iniciativa privada e pelas chamadas organizações públicas não-estatais. Passam a se constituir em serviços exclusivos do Estado somente o subsídio à educação básica, 
a previdência social básica, a compra de serviços de saúde e o controle do meio ambiente (NEVES, 2004, p. 3).

Um dos aspectos centrais apresentados no documento é a necessidade do fortalecimento do Estado para que "[... ] sejam eficazes sua ação reguladora, no quadro de uma economia de mercado, bem como os serviços básicos que presta e as políticas de cunho social que precisa implementar" (BRASIL, 1995, p. 7).

Nessa direção, no Plano Diretor (1 995), defende-se que "[...] a administração pública seja permeável a maior participação dos agentes privados e das organizações da sociedade civil, deslocando-se a ênfase dos procedimentos (meios) para os resultados (fins)" (COSTA, 2010, p. 168, grifo do autor).

Em defesa de um novo modelo de administração pública, sob bases modernas e racionais, segue explícita, no documento, a crítica ao modelo burocrático. Nesse sentido, o "salto adiante", conforme apontado no Plano, seria uma administração pública gerencial, voltada para controle dos resultados, na qual o cidadão se torna "cliente privilegiado" dos serviços prestados pelo Estado, e os servidores têm nova visão de seu papel.

No Plano Diretor (1995), destaca-se que a crise, num sistema capitalista, é decorrente do funcionamento irregular do Estado ou do mercado. Nos anos de 1920 e 1930, conforme o documento, uma crise econômica foi gerada pelo mau funcionamento do mercado. Mas, nos anos de 1980, foi a crise do Estado que pôs em xeque o modelo econômico vigente, o que justifica a necessidade de redefinição do papel do Estado a partir dos anos de 1990.

Nessa perspectiva, no Plano Diretor de Reforma do Aparelho do Estado, a crise do Estado é definida como:

(1) uma crise fiscal, caracterizada pela crescente perda do crédito por parte do Estado e pela poupança pública que se torna negativa; (2) o esgotamento da estratégia estatizante de intervenção do Estado, a qual se reveste de várias formas: o Estado do bem-estar social nos países desenvolvidos, a estratégia de substituição de importações no terceiro mundo, e o estatismo nos países comunistas; e (3) a superação da forma de administrar o Estado, isto é, a superação da administração pública burocrática (BRASIL, 1995, p. 11). 
Nessa ótica, com a análise acerca do papel do Estado e da crise, foram questionados, no documento, a forma de intervenção econômica e social do Estado e o próprio aparelho do Estado, pela rigidez dos processos e excesso de normas e regulamentos.

Conforme explicado no Plano (1995), duas respostas à crise foram inadequadas: uma, ignorá-la após a transição democrática; outra, a neoliberal, caracterizada pelo Estado mínimo. Considerou-se, então, mais consistente a resposta dos anos 1990 de "reforma ou reconstrução do Estado", para resgatar sua autonomia financeira e sua capacidade de implementar políticas públicas.

Nessa perspectiva, para reformar o Estado, ressaltou-se, além do ajuste fiscal, o processo de publicização que é considerado, no documento, tão importante quanto a privatização. Este primeiro trata-se, porém,

[...] da descentralização para o setor público não-estatal da execução de serviços que não envolvem o exercício do poder de Estado, mas devem ser subsidiados pelo Estado, como é o caso dos serviços de educação, saúde, cultura e pesquisa científica [...] (BRASIL, 1995, p. 131.

A partir dessa parceria entre Estado e sociedade, "[...] o Estado reduz seu papel de executor ou prestador direto de serviços, mantendo-se, entretanto, no papel de regulador e provedor ou promotor destes, principalmente dos serviços sociais [...]" (BRASIL, 1995, p. 13). Nessa direção, estabelecida tal parceria, pretende-se reforçar a governança do Estado, superando a administração burocrática, rígida e ineficiente em favor de uma administração mais voltada para o cidadão, que seria a administração gerencial, flexível e eficiente. Com isso, é fortalecido o poder do Estado de governar, dada "[...] sua legitimidade democrática e o apoio com que conta na sociedade civil" (BRASIL, 1995, p. 13).

Conforme destaca Coutinho (2005), a reforma do Estado, nas democracias modernas, tem-se dado em nível político e administrativo, assim explicitados:

No plano político, destaca que cada vez mais há participação e controle direto da administração pública pelos cidadãos, particularmente no nível local. Essa, por sinal, uma tendência percebida nos últimos anos da década de 90 e início do século XXI com as políticas de municipalização dos serviços de saúde, educação e assistência social. No plano administrativo ocorre a defesa da administração pública gerencial-burocrática (COUTINHO, 2005, p. 7). 
Nesse sentido, para responder às demandas sociais, o Estado direcionou-se às parcerias, que foi "[... ] um passo essencial à expansão e consolidação do terceiro setor no Brasil, abrindo espaços para a disputa dos setores essenciais, aliviando o Estado de suas demandas" (COUTINHO, 2005, p. 59). Desse modo, enfatizou-se a participação da sociedade no controle das políticas sociais.

empresariado nacional, por sua vez, além de participar nas discussões sobre as políticas sociais, ganha espaço também na implementação dessas políticas, mediante a instituição de parcerias com o setor público.

A parceria entre o setor público e privado, no Brasil, foi legalmente instituída no governo Luís Inácio Lula da Silva pela Lei Federal da Parceria PúblicoPrivada, n 11 .079, de 30 de dezembro de 2004, que institui "[...] normas gerais para licitação e contratação de parceria público-privada no âmbito dos Poderes da União, dos Estados, do Distrito Federal e dos Municípios" (BRASIL, 2004, p. 1).

Na contratação de parceria público-privada, como explicitada no Art. $4^{\circ}$ da Lei n $n^{\circ} 11.079$, serão observadas as seguintes diretrizes:

I - eficiência no cumprimento das missões de Estado e no emprego dos recursos da sociedade;

II - respeito aos interesses e direitos dos destinatários dos serviços e dos entes privados incumbidos da sua execução;

III - indelegabilidade das funções de regulação, jurisdicional, do exercício de poder de polícia e de outras atividades exclusivas do Estado;

IV - responsabilidade fiscal na celebração e execução das parcerias;

$V$ - transparência dos procedimentos e das decisões;

$\mathrm{VI}$ - repartição objetiva dos riscos entre as partes;

VII - sustentabilidade financeira e vantagens socioeconômicas dos projetos de parceira (BRASIL, 2004).

No que diz respeito à questão financeira, conforme o Art. $6^{\circ}$ dessa Lei, haverá a contraprestação da Administração Pública. $O$ contrato de parceria, conforme o parágrafo único do Art. $6^{\circ}$ da Lei de Parceria Público-Privada, "poderá prever o pagamento ao parceiro privado de remuneração variável vinculada ao seu desempenho, conforme metas e padrões de qualidade e disponibilidade 
definidos no contrato" (BRASIL, 2004). Há, nesse sentido, uma parceria entre o setor privado e o público, estabelecendo-se em lei, para o compartilhamento de atividades, via contratos e contraprestações.

As instituições privadas "parceiras" passam, então, a intervir no espaço público, refletindo também uma característica da nova administração pública ou modelo gerencial, que considera ser o setor privado mais eficiente e preparado para efetivar, no setor público, medidas para obtenção de bons resultados.

\section{Gerencialismo e educação}

No campo educacional, pautado no redimensionamento da administração pública com a reforma do Estado, adotou-se o modelo gerencial de gestão, que busca imprimir, no espaço público, a lógica de empresa, atribuindo aos cidadãos, definidos como usuários dos serviços públicos, o papel de clientes e, ao gestor, o papel de gerente. No âmbito da escola pública, especificamente, tal modelo repercute como expressão de um processo acelerado de modernização, que conta com a participação ativa do empresariado na definição e execução das políticas públicas.

A lógica gerencial de eficiência e focalização dos resultados, apresentando, ainda, conforme alerta Coutinho (2005), características de competição, descentralização e redução dos níveis de hierarquia, "[...] permeabilizou o serviço público às intervenções do privado e às organizações da sociedade civil de caráter não-governamental", onde "[...] o cidadão passa a ser cliente preferencial dos serviços públicos" (COUTINHO, 2005, p. 71).

Nesse sentido, a gestão gerencial, como expressão também de um projeto de sociabilidade da hegemonia burguesa, precisa ser analisada tendo em vista suas implicações no setor público e no contexto das escolas e sistemas de ensino. Tal análise deve, ainda, considerar as determinações legais sobre a gestão democrática ou o modelo gerencial e seus princípios norteadores, bem como o significado de participação que, na perspectiva desse modelo, pressupõe um ressignificado papel ativo da sociedade civil. Nesse sentido,

A reforma do Estado, na perspectiva de sua retração para as políticas sociais e, particularmente, para a política educacional, destitui a sociedade civil da participação política no sentido republicano. $\bigcirc$ que se conclama desde então é uma participação do 
tipo voluntariado, da ajuda mútua dos amigos da escola, enfim, das parcerias, uma vez que nestas estão as bases daquilo que se denominou como a participação pretendida pela terceira via e terceiro setor na lógica do público não-estatal. Em tal lógica, o ensino está sendo destituído da pedagogia da contestação, da transformação. Nesse lugar, caberia agora a pedagogia da conformação e da conciliação imposta pelo pensamento hegemônico (PERONI; OLIVEIRA; FERNANDES, 2009, p. 773 -774).

No contexto das reformas educacionais da década de 1990, a gestão foi redimensionada com novas estratégias para a escola pública. Nesse período, nos países desenvolvidos e em desenvolvimento, tais reformas

[...] evidenciaram a necessidade de modernizar a gestão educacional, quer no âmbito dos ministérios e das secretarias, quer no âmbito das escolas, consideradas ineficientes e burocráticas. Dadas as circunstâncias, a descentralização da gestão apresenta-se como uma estratégia fundamental para garantir a melhoria da qualidade da escola, aumentar sua eficiência, sua eficácia e produtividade (CASTRO, 2007, p. 116).

234 Vive-se, portanto, no Brasil, um processo de modernização da gestão, fortalecida, conforme Castro (2007), a partir da última década do século XX, com o processo de reforma do aparelho do Estado.

Cabral Neto, nessa mesma direção9 , enfatiza que:

A lógica gerencial é incorporada ao modelo de gestão educacional, o qual coloca como eixo fundante, para a melhoria do sistema, a participação de usuários nos serviços educacionais. Tal modelo inclui, também, a defesa da responsabilização dos gestores e o protagonismo dos pais, dos alunos, dos professores nas tomadas de decisões da escola, aspectos inerentes à nova gestão pública [...] (CABRAL NETO, 2009, p. 198).

No âmbito das escolas, influenciadas pelas transformações na gestão pública, a reforma gerencial deve ser analisada como:

[...] uma modificação estrutural do Estado e não pode ser confundida como uma mera implantação de novas formas de gestão. Pelas possibilidades de participação, de autonomia e descentralização previstas nas suas diretrizes, ela se apresenta como 
fundamental no aperfeiçoamento da governabilidade democrática, à medida que pressupõe e procura aperfeiçoar os mecanismos de responsabilização e transferência da administração pública. No entanto, o modo como vem sendo operacionalizada não condiz com a gestão democrática da educação, pois, apesar de utilizar os mesmos conceitos, o faz de forma diferenciada, convidando a comunidade escolar para executar tarefas previamente pensadas e planejadas, sem a presença dos atores educacionais (CASTRO, 2007, p. 1401.

Essa discussão, mais especificamente no que concerne à gestão educacional e escolar, impõe novos desafios aos educadores, uma vez que também promove mudanças na participação e no processo decisório no interior da escola pública; nas formas de avaliação e estratégias para que se alcancem os melhores resultados; no significado do ser cidadão, agora cliente dos serviços públicos; corroborando, além disso, a competição através de políticas meritocráticas; e atribuindo novos sentidos à qualidade que, nesse contexto, estaria pautada em padrões de eficiência do setor privado.

Ainda analisando o processo de modernização da gestão escolar, Cabral Neto (2009) aponta o Plano de Desenvolvimento da Escola (PDE) ${ }^{10}$ como um instrumento de configuração do gerencialismo no âmbito educacional, que adota mecanismos de gerenciamento com a finalidade de "melhorar a qualidade do ensino que a escola oferece" (CABRAL NETO, 2009, p. 200). O PDE-escola, conforme o autor, elege alguns requisitos, quais sejam: as ações localizadas na aprendizagem e no sucesso do aluno; a liderança do dirigente escolar em todo o processo de elaboração e implementação do PDE; o comprometimento de todas as pessoas envolvidas no processo para que as ações tenham sucesso.

É possível, ainda, vislumbrar repercussões do modelo gerencial, como já pontuado, através da ênfase no setor privado enquanto capaz de promover melhorias no setor público. E, nesse sentido, constata-se, em redes públicas de ensino de todo país, a participação efetiva do empresariado com programas e projetos para escola pública. Dentre institutos e fundações envolvidos ativamente em políticas implementadas no setor público, em especial nas políticas educacionais, grande influência exercem, por exemplo, o Instituto Ayrton Senna ${ }^{11}$; o Instituto Camargo Corrêa e a Fundação Pitágoras ${ }^{12}$, além de diversas empresas 
engajadas em "solucionar" problemas na educação e reconhecidas pela atuação com "responsabilidade social".

Nessa ótica, torna-se imprescindível discutir essas transformações, decorrentes da reforma do aparelho do Estado, considerando, sobretudo, suas repercussões no campo da Educação e no contexto específico da escola pública, visando à compreensão da influência do gerencialismo na gestão escolar.

Pode-se afirmar, nesse sentido, que programas e projetos implementados nas escolas públicas, na perspectiva gerencial, são também decorrentes desse movimento de reforma na administração pública, desse processo de modernização da gestão. Incluídos, portanto, no contexto das parcerias público-privadas, e apresentados como instrumentos eficientes para que se alcancem bons resultados, a partir da atuação de um grupo restrito de líderes/gerentes, tornam-se grande desafio a ser enfrentado por todos aqueles que anseiam pela democratização da escola pública.

\section{Conclusão}

236 Com a análise teórica do documento do CLAD, pode-se perceber os principais fundamentos do gerencialismo e como esse conteúdo está presente nas políticas educacionais implementadas no Brasil, desde a década de 1990. O Plano Diretor de Reforma do Aparelho do Estado (1995) apresenta as bases da reforma gerencial, na especificidade brasileira, argumentando em favor da reforma do Estado e da modernização da gestão, intensificando as reformas no campo educacional.

Os defensores da reforma gerencial utilizam conceitos da democracia, como participação, autonomia, descentralização, propondo uma redefinição das relações entre Estado e sociedade civil. Porém, o que pode ser observado, no espaço público, é a ressignificação desses conceitos, em busca de eficiência e produtividade.

As principais bases do gerencialismo, já mencionadas nesse texto, e presentes nas políticas públicas, consistem no incentivo às parcerias, à mobilização e à participação ativa da sociedade civil, com ação efetiva do empresariado na execução das políticas; consistem, ainda, na adoção de mecanismos de avaliação do desempenho e estratégias de premiação; na defesa da autonomia do 
sistema; descentralização; flexibilização da administração pública; qualificação dos gerentes; racionalização.

Nessa perspectiva, defende-se, para o século XXI, o Estado necessário; busca-se aumentar a governança do Estado, unindo-se o neoliberalismo à justiça social, na busca de obter, cada vez mais, o consenso da sociedade.

Cumpre, pois, atentar aos desafios postos, pela reforma gerencial, à democratização da gestão educacional no Brasil, uma vez que se vem evidenciando a interferência do empresariado na implementação das políticas educacionais no país, visando instaurar, cada vez mais, os princípios da eficiência, eficácia e produtividade no setor público.

\section{Notas}

1 A Teoria da Escolha Racional ou escolha pública (public choice) pode ser considerada uma análise econômica da política, que busca estudar o setor público a partir do comportamento individual dos agentes que o integram (PARDO, 1984, p. 21 apud COSTA, 2010).

2 Conforme Costa (2010), essas ideias eram veiculadas, na Inglaterra, primeiro através do Institute of Economics Affairs, criado em 1955 e, mais tarde, do Centre for Policy Studies e do Adam Smith Institute.

3 Nessa fase, os conceitos chaves são "accountability e equidade na prestação de serviços públicos, o que nos remete ao conceito de cidadania que requer uma participação ativa na escolha dos dirigentes, na elaboração das políticas e na avaliação dos serviços públicos" (CASTRO, 2007, p. 129). A accountability também é entendida como "mecanismos de responsabilização" $[\ldots]$.

4 "El CLAD es un organismo internacional que Institucionalmente participa en otras instancias internacionales y es la secretaría técnica permanente de las Conferencias lberoamericanas de Ministros de Administración Pública y Reforma del Estado que se realizan en el marco de las Cumbres Iberoamericanas de Jefes de Estado y de Gobierno" (Acerca Del CLAD. Disponível em: http:// www.clad.org/portal; Acesso em: 23 abr. 2013).

5 C Conselho Diretor do CLAD é composto pelas máximas autoridades responsáveis pela modernização da Administração Pública e da reforma do Estado dos 25 países membros (CLAD. In: Uma Nova Gestão Pública para América Latina, 1998).

6 Governança: é entendida pelo CLAD (1998, p. 08) como "a capacidade do Estado de transformar em realidade, de forma eficiente e efetiva, as decisões politicamente tomadas".

7 Segundo Brooke (201 1), os estados do Amazonas, Ceará, Pernambuco, Rio de Janeiro, Minas Gerais e São Paulo, já têm experiência com o uso de incentivos salariais para professores. Salienta, ainda, que o estado do Espírito Santo e o Distrito Federal já estabeleceram os procedimentos a serem seguidos, mas ainda não implementaram suas políticas. Acrescentamos o 
estado da Paraíba e o município de Campina Grande, que também vêm intensificando políticas meritocráticas.

8 "O aparelho do Estado é entendido como a administração pública em sentido amplo, ou seja, a estrutura organizacional do Estado, em seus três poderes (Executivo, Legislativo e Judiciário) e três níveis (União, Estados membros e Municípios)" (BRASIL, 1995, p. 12).

9 Esses fundamentos destacados por Cabral Neto (2009) e Castro (2007), acerca do modelo gerencial na gestão educacional e escolar, também podem ser evidenciados na implementação do Sistema de Gestão Integrado (SGI) em Secretarias de Educação e escolas municipais, a qual propõe mudanças na gestão e atribui novos papéis a gestores, professores e demais atores do contexto da escola visando ao alto desempenho e à construção de um espaço denominado inovador.

10 "O PDE-Escola é uma ferramenta gerencial que auxilia a escola a realizar melhor o seu trabalho: focalizar sua energia, assegurar que sua equipe trabalhe para atingir os mesmos objetivos e avaliar e adequar sua direção em resposta a um ambiente em constante mudança. É considerado um processo de planejamento estratégico desenvolvido pela escola para a melhoria da qualidade do ensino e da aprendizagem" (PDE- Apresentação. Disponível em: http://portal.mc.gov.br).

11 (CF, PERONI; ADRIÃO 2005, 2006, 2008).

12 Verificar as "missões" de Institutos e fundações, reconhecidos pela atuação em políticas sociais, em especial educacionais. Disponível em: http://senna.globo.com; http://www.fundacaopitagoras.com.br/; http://www.institutocamargocorrea.org.br.

\section{Referências}

ABRUCIO, Fernando Luiz. $\bigcirc$ impacto do modelo gerencial na Administração Pública: um breve estudo sobre a experiência internacional recente. Cadernos ENAP, Brasília, n. 10, p. $1-50,1997$.

BRASIL. Câmara da Reforma do Estado. Plano Diretor da Reforma do Aparelho do Estado. Brasilia, 1995. Disponível em: <www.planalto.gov.br/publi_04/.../plandi.htm > Acesso em: 10 fev. 2010.

BRASIL. Lei $\mathbf{n}^{\circ} \mathbf{1 1}$.079, de $\mathbf{3 0}$ de dezembro de 2004. Lei Parceria Público-Privada. Institui normas gerais para licitação e contratação de parceria público privada no âmbito da administração pública. Brasília, 2004.

BROOKE, Nigel. As novas políticas de incentivo salarial para professores: Uma avaliação. In: FONTOURA, Helena Amaral da (Org.). Políticas públicas, movimentos sociais: desafios à pós-graduação em educação em suas múltiplas dimensões. Rio de Janeiro: ANPEd Nacional, 2011 , p. 163 - 188. (Coleção ANPED Sudeste, Livro 3). 
CABRAL NETO, Antônio. Gerencialismo e gestão educacional: cenários, princípios e estratégias. In: FRANÇA, Magna; BEZERRA, Maria Costa (Org.) Política educacional: gestão e qualidade do ensino. Brasília: Liber livro, 2009.

CARVALHO, Elma Júlia Gonçalves. Reestruturação produtiva, reforma administrativa do estado e gestão da educação. Educação \& Sociedade, Campinas, v. 30, n. 109, p. $1139-1166$, set./dez. 2009. Disponível em: <http://www.cedes.unicamp.br> Acesso em: 20 out. 2011

CASTRO, Alda Maria Duarte Araújo. Gerencialismo e Educação: estratégias de controle e regulação da gestão escolar. In: CABRAL NETO, Antônio; CASTRO, Alda Maria Duarte Araújo; FRANCCA, Magna; QUEIROZ, Maria Aparecida de (Org.). Pontos e contrapontos da política educacional: uma leitura contextualizada de iniciativas governamentais. Brasília: Líber livro, 2007.

CLAD. Uma nova gestão pública para América Latina. Documento do CLAD, 1998. (Conselho Científico do Centro Latino Americano de Administração para o desenvolvimento).

COSTA, Frederico Lustosa da. Reforma do Estado e contexto Brasileiro: crítica do paradigma gerencialista. Rio de Janeiro: Editora FGV, 2010.

COUTINHO, Adelaide Ferreira. As organizações não governamentais e a educação básica oferecida aos pobres: do consenso da oferta à ação privatizante. 2005. 338 f. Tese (Doutorado em Educação) - Programa de Pós-Graduação em Educação, Universidade Federal do Rio Grande do Norte, Natal, 2005.

NEVES, Lúcia Maria Wanderley. As reformas da educação escolar brasileira e a formação de um intelectual urbano de novo tipo. In: REUNIÃO ANUAL DA ANPEd, 27.; 2004, Caxambu. Anais... Caxambu: Associação Nacional de Pós-Graduação e Pesquisa em Educação, 2004. Disponivel em: <http://www.anped.org.br/reunioes/27/gt05/+0510.pdf> Acesso em: 15 out. 2012.

NEVES, Lúcia Maria Wanderley. A sociedade civil como espaço estratégico de difusão da nova pedagogia da hegemonia. In: NEVES, Lúcia Maria Wanderley (Org.). A nova pedagogia da hegemonia: estratégias do capital para educar o consenso. São Paulo: Xamã, 2005.

PERONI, Vera Maria Vidal; OLIVEIRA, Regina Tereza Cestari de; FERNANDES, Maria Dilnéia Espíndola. Estado e terceiro setor: as novas regulações entre público e o privado na gestão da educação básica brasileira. Educação \& Sociedade, Campinas, v. 30, n. 108, p. 761-778, out. 2009. Disponível em: <http://www.cedes.unicamp.br> Acesso em: 12 jun. 2010. 


\author{
Ms. Sonayra da Silva Medeiros \\ Prefeitura Municipal de Campina Grande |Paraíba \\ Secretaria Municipal de Educação \\ Grupo de Pesquisa | Coletivo de Estudos sobre Política Educacional \\ E-mail | sonayramedeiros@hotmail.com \\ Dra. Melânia Mendonça Rodrigues \\ Universidade Federal de Campina Grande |Paraíba \\ Unidade Acadêmica de Educação \\ Grupo de Pesquisa | Coletivo de Estudos sobre Política Educacional \\ E-mail | melania.r@uol.com.br
}

